\title{
LOS AÑOS SESENTA
}

\author{
POR \\ ADOLFO PRIETO \\ University of Florida
}

La extrema atención acordada por la crítica al llamado boom de la literatura latinoamericana ha contribuido, por cierto, a privilegiar la percepción de un fenómeno que afectó el comportamiento de ciertos niveles de la cultura urbana en varios países de la América de habla española. Controvertido en sus términos, heterogéneo, ambiguo, el fenómeno del boom pudo, sin embargo, seducir por ese don de simultaneidad, por esa condición polifónica que parecía unir en un mismo registro las voces de todo un continente. No había ocurrido nada similar desde los años augurales de la primera posguerra. Pero lo que entonces fue la acción de grupos de escritores dispersos que forzaban las distancias para leerse a sí mismos ahora era el funcionamiento de un soberbio aparato de difusión y promoción cultural al servicio y por el servicio de una nueva clase de lectores altamente adiestrados.

La serie de estudios presentados al «Latin American Program» de1 Woodrow Wilson International Center, en Washington, y los trabajos de allí derivados al volumen colectivo Más allá del boom. Literatura y mercado, han iniciado una firme revisión del hecho, y sus conclusiones, a pesar de la variedad de tonos en que están formuladas, permiten avizorar las certidumbres de un verdadero balance ${ }^{1}$.

$\mathrm{Y}$ es la madurez de óptica lograda para percibir y delimitar el suceso más llamativo de la literatura latinoamericana durante la década del sesenta la que parece sugerir, precisamente, la oportunidad de examinar el desarrollo de las literaturas nacionales durante el mismo período. De procurar, al menos, una carta de reconocimiento en la que puedan fijarse las confluencias globales de ese nudo de condensación cultural, pero en

\footnotetext{
${ }^{1}$ Más allá del boom. Literatura y mercado (México: 1981).
} 
la que exista, asimismo, el espacio necesario para fijar las circunstancias irreductibles a ese proceso, para situar los textos y los actos de lectura que no fueron asimilados o asimilables al mismo.

A comienzos de los sesenta la Argentina ensayaba un débil y condicionado sistema de representación política que daría paso, finalmente, a la instalación de un régimen militar, en 1966. Pero las tremendas tensiones sociales que ocultaban esos repliegues y deslizamientos no irrumpieron a la superficie sino en el cierre de la década, por lo que este nivel de la experiencia colectiva, visto retrospectivamente, no acierta a calificarse sino por su incomodidad crónica, su confusión, su sentimiento de amenaza latente y su canjeable amontonamiento de hechos y de figuras. Más que el signo político, entonces, más que el lugar cedido al congelamiento o la atomización de la expresión política, el signo que efectivamente se visualiza como caracterizador de la dinámica social de esos años es el de la articulación de vastos sectores de la población con lo que pareció ser el fruto maduro de la era industrial de Occidente: la sociedad de consumo.

La Argentina, por supuesto, estaba lejos de cubrir las etapas y peripecias de una auténtica sociedad industrial, pero pudo ser temprana y extremadamente sensible a las incitaciones y reclamos de su estadio último. Las viejas estructuras modeladas por la dependencia económica, un moderado crecimiento del aparato de producción, y lo que entonces se pensó una astuta invención lugareña, la inflación controlada, fueron los vasos comunicantes del fenómeno y sus agentes locales. Sin contar con las expectativas de vida de una numerosa clase media, forjada en generaciones de sueños postergados.

Mal que bien instalada en sus soportes materiales, esta versión particular de la sociedad de consumo dio curso también a algunos de sus presupuestos morales e ideológicos; aclimató parecidas normas de permisividad; puso en circulación algunos de sus mitos; aduló a la juventud; estimuló, como nunca, la producción e intercambio de objetos culturales; aplaudió (y absorbió) los brotes de la contracultura que buscaba suprimirla ${ }^{2}$.

Fue una versión tumultuosa, colorida y, en términos comparativos, avasallante. Pero fue una versión que debió compartir el escenario, de todas maneras, con las fuerzas de tensión, la andadura de época y los hábitos mentales que venían del pasado inmediato. El reclutamiento del lector-consumidor que sostendría el boom editorial de los sesenta, por

${ }^{2}$ Excelente material para la caracterización de los años sesenta en Occidente, en Gerald Howard, Editor, The Sixties (New York: 1982). 
ejemplo, respondió holgadamente y con más que apreciable fidelidad a las pautas educativas y a la temperatura emocional de los años de formación. Todo el andamiaje de la instrucción pública durante los años cincuenta, debe recordarse, fue afectado en profundidad por la presión de los signos políticos excluyentes de peronismo y de antiperonismo. Pero el repertorio de respuestas con que ambas tendencias buscaron dirimir o racionalizar el más agudo conflicto padecido por la sociedad argentina hasta entonces abrevó en las mismas fuentes; apeló al mismo sentido de pertenencia a un contexto histórico apremiante; a la misma necesidad de identificarse identificando el contorno.

No debe sorprender, entonces, que la Editorial de la Universidad de Buenos Aires, creada a fines de 1959, inaugurara los sesenta con un descubrimiento y una verificación. Lo nuevo fue la cantidad de ejemplares necesarios para atender la demanda de un público calculado en otras dimensiones. Lo previsible, la lista de títulos elegidos y la orientación de sus colecciones. La serie del siglo y medio, ofrecida a la venta en paquetes de cuatro volúmenes, agotó un millón y medio de ejemplares en poco más de dos años, y se aprestaba a repetir la cifra en los dos siguientes. En 1962, cincuenta mil ejemplares de la edición popular de Martín Fierro se vendieron en veinticinco días y otros cincuenta mil se agotaron también en un tiempo desacostumbradamente corto ${ }^{3}$.

Clásicos de la literatura argentina sirvieron así para reconocer el circuito de lectura que caracterizaría, por sus dimensiones, uno de los aspectos sobresalientes de la vida cultural de la década; y sirvieron también para introducir, por el camino real, el nombre de algunos de los autores contemporáneos. Estos autores, si nos atenemos a las citas disponibles, representaban también, sin sorpresa, a la literatura dominante en el recodo final de los años cincuenta.

Borges parecía entonces neutralizado en su condición de clerc y de habitante único del Olimpo doméstico; Mallea, una sombra congelada en el silencio de sus fervorosos lectores de ayer; Martínez Estrada, una voz sin audiencia discernible y una presencia extraña. Sábato y Viñas, que habían asumido esa representación y la compartían, a pesar de sus obvias diferencias, pudieron mantenerla con holgura y revalidarla en el comienzo de los sesenta con Sobre héroes y tumbas (1962) y Dar la cara

${ }^{3}$ Sobre el movimiento editorial de la época pueden consultarse Jorge B. Rivera, Apogeo y crisis de la industria del libro: 1955-1970, en Capitulo, La historia de la literatura argentina, 99 (Buenos Aires: 1981); Rodolfo A. Borello, «Autores, situación del libro y entorno material de la literatura en la Argentina del siglo xx», en Cuadernos Hispanoamericanos, núms. 322/323 (Madrid: 1977), y Emilio Carilla, Autores, libros y lectores en la literatura argentina (Tucumán: 1979). 
(1962), respectivamente. Resonancias existencialistas; historia; lenguaje mediador; personajes situados; triunfo del código referencial. Si a estas notas se agrega la de la apelación más o menos explícita a la conciencia moral del lector, matizadas variantes del realismo crítico, se avanzará en el trazado de una fórmula apta para abarcar una amplia nómina de narradores, de la que pueden citarse los nombres de Germán Rozenmacher, Marta Lynch, Beatriz Guido, Humberto Constantini, Rodolfo Walsh, Pedro Orgambide, Elvira Orphée y acaso Abelardo Castillo, Jorge Riestra y Juan José Hernández.

Hasta 1964, el predominio de esta concepción de la literatura, con sus territorios privilegiados y sus exclusiones, pareció prácticamente indiscutible. Pero la aparición de Rayuela, a mediados del año anterior, fue creando en el término de pocos meses un espacio de recepción propio, en el que tanto las viejas como las nuevas obras de Cortázar y las de algunos de sus discípulos y allegados vendrían a insertarse y a permanecer por el resto de la década.

Para establecer el origen y la cronología de esta verdadera división de las aguas en el circuito de producción y de lectura de esos años nada parecerá tan razonable como acudir al archivo de la publicación periódica que siguió más de cerca el proceso cultural de la época, y que contribuyó, en buena hipótesis de trabajo, a orientarlo, proveerlo de un lenguaje inequívoco y hasta comprometerlo en la configuración de algunas de sus tendencias particulares.

El semanario Primera Plana comenzó a difundirse en noviembre de 1962. Imitación de las disposiciones gráficas y del estilo de Time y de L'Express, tomó también de ellos la facultad —o la pretensión- de convertirse en un foro en el que pudieran coincidir los intereses de la política, la economía y la cultura, sin las reservas ideológicas y la limitación facciosa que habían caracterizado, hasta entonces, tanto a la prensa general como especializada. Su contribución vernácula consistió en un ajuste de esos ingredientes, tomando abierto partido en los campos político y económico, y concediendo un amplio escenario, mayor que el de los modelos, a todas las expresiones de cultura que parecieran confirmar el espíritu de los tiempos ${ }^{4}$.

'Primera Plana apareció ininterrumpidamente entre el 13 de noviembre de 1962 y el 4 de agosto de 1969. En esa fecha, un decreto del gobierno del general Onganía prohibió su circulación. Al reaparecer, un año después, publica lo que tal vez pueda considerarse el primer anuncio del término del boom, un fenómeno al que el semanario ayudó ostensiblemente a crecer. La nota es del 27 de octubre de 1970 y se titula Lo que el boom no se llevó. Otros semanarios de consulta no desdeñable son Confirmado, Análisis y Panorama. 
En su primer número, el semanario titulaba una de sus notas: «Una extraña forma de teatro en Nueva York: El happening». En su segundo destacaba la cuidada edición popular de Martín Fierro, los cincuenta mil ejemplares vendidos de la misma, los nuevos planes de comercialización de la Editorial de la Universidad de Buenos Aires y sus espectaculares éxitos de promoción. En el tercero incluía un perfil del Departamento de Sociología de esa Universidad, que ya entonces se insinuaba y que efectivamente sería el núcleo de modernización más activo de la Universidad hasta la intervención militar de la misma en 1966.

Ojos y oídos alertas a cualquier indicio de renovación, de ruptura, de cambio. En agosto de 1963, en una nota con extensas ilustraciones gráficas, presenta al recién inaugurado Instituto Di Tella: «Desde ayer, en Florida 940, el mundo moderno está al alcance de todos. Basta atravesar estos umbrales para comprender que, con los mismos títulos que la política y la economía, las artes visuales forman parte de la vida del hombre, la integran y la explican.» Declaración de principios, entonces, y declaración de fidelidad a la institución que mayor cantidad de material informativo le proporcionaría en los años por venir.

En el mismo mes de agosto, sin embargo, el comentarista que tiene a su cargo la reseña de Rayuela vacila, se desconcierta, se siente obligado a establecer conexiones con los juicios en vigor. Titula su nota: «Novela espesa con sabias reminiscencias», y en el texto las declara: Roberto Arlt y Marechal, dos autores precisamente rescatados de su marginalidad por la presión modeladora de los años cincuenta. Agrega: «Retenido en el cultivo del cuento fantástico por una moda exhausta, Julio Cortázar necesitó diez años para conocerse a sí mismo como novelista. Lo hizo con Los premios, en 1961. Atrás quedaban media docena de libros cuya insistente sutileza no disimulaba la parvedad de su inspiración.» Rayuela, por sobre trucos y sofisticaciones, transmite «una potente voluntad de forma». En el mismo número se proporciona la lista de best-sellers. Rayuela figura junto con Sobre héroes y tumbas. Semanas antes, los títulos eran los de la novela de Viñas Dar la cara y Cabecita negra, de Germán Rozenmacher.

Debieron' transcurrir varios meses desde la publicación de esta nota para que el crítico o los críticos que cubrían la sección literaria del semanario advirtieran el efecto de sorpresa y asimilaran los ecos que la novela de Cortázar despertaba en su creciente número de lectores. Meses, antes de que se decidieran a admitir y decidieran trabajar por la admisión del fenómeno Cortázar como un fenómeno separado del horizonte literario hasta entonces vigente. En mayo de 1964 apareció un comentario muy elogioso sobre Final de juego, y el 27 de octubre del 
mismo año, la edición correspondiente incluía foto de tapa de Cortázar y una sección de cinco páginas, la más extensa dedicada por la revista a un escritor, con abundante información y material gráfico.

Pero 1964 fue todavía «el volcán de los best-sellers», un hecho económico y un síndrome de la vida colectiva argentina; una explosión de energía que se recortaba en los límites del propio país y se reconocía en el rostro de sus propios escritores. Y 1965, «el año de la literatura argentina», una comprobación jubilosa que el semanario aprovechó para entrevistar a algunos de sus más visibles agentes y beneficiarios. Sábato, con el respaldo de los cincuenta mil ejemplares impresos de Sobre héroes y tumbas, reflexionaba: «En el público argentino se ha despertado un interés casi ansioso por develar lo que podríamos llamar secreto de nuestra realidad. Se espera, y no siempre con razón, que sean los escritores quienes desenmascaren ese secreto.» Para Marta Lynch, «el éxito empezó cuando los escritores argentinos resolvieron mirar dentro del país». Juan José Sebreli atribuía esa resonancia a la crisis político-social en que se debatía el país, y el más joven de los entrevistados, Abelardo Castillo, después de algunas reservas, admitía: "Ya se ve, sí, que algo pasa. Y si bien el fenómeno no es nuevo (referencia a los tiempos de Boedo y Claridad), parece que, por lo menos, hemos redescubierto los argentinos al escritor argentino» 5 .

Para entonces, de todas maneras, con esa aceleración vertiginosa del ritmo que caracterizó el meridiano cronológico de la década, otros hechos vinieron a decidir en la laboriosa distinción que la presencia de Cortázar proponía. A partir de 1965, en efecto, la sucesiva y contundente aparición de La ciudad y los perros, El siglo de las luces, Tres tristes tigres, Cien años de soledad, Paradiso y la notoria fluidez del nuevo circuito de producción y de lectura latinoamericano, se convirtieron en un foco de gravitación lo suficientemente poderoso como para modificar las líneas internas y el juego de relaciones en el circuito de producción y de lectura argentino.

Cortázar fue considerado, desde el principio, miembro natural de esa élite de narradores (una élite que segregó de sí misma como su precursor irrefutable al irrefutable Borges ${ }^{6}$ ), y su obra, palanca decisiva en la proyección del libro latinoamericano. Desde esta perspectiva, desde el

5. Primera Plana, 26 de octubre de 1965.

- En este proceso colaboró, seguramente, el reconocimiento de la crítica europea a la obra de Borges. En cuanto al pasaje de la situación de escritor a personaje, una de las innovaciones introducidas en el nuevo contexto cultural, véanse las atinadas observaciones de Angel Rama en Más allá del boom. Literatura y mercado, op. cit. 
mirador múltiple de la crítica internacional y del consenso, pareció inevitable admitir el estatuto propio de una literatura para nada ansiosa de indagar o de reflejar el entorno; para nada ansiosa, por tanto, de ratificar la condición que la mayoría de los responsables del boom editorial argentino aceptaban reconocer en sus escritos. Dicho en los términos usados por Susan Sontag, en 1965, para describir la situación cultural en los Estados Unidos, el estatuto propio de una literatura que buscaba convertirse en una extensión y no en una crítica de la vida. De un arte que buscaba superar la vieja brecha que separaba la moral de la vida, no negando el rol de la evaluación moral, sino transfiriéndolo a niveles de operación subliminales: no negando la secular preferencia contenidista por el exclusivo placer de las formas, sino privilegiando a éstas sobre las facilidades del discurso explícito ${ }^{7}$.

La nueva sensibilidad a la que apelaba Susan Sontag en su ensayo para explicar la epifanía de una nueva concepción del arte, florecía entonces en las principales ciudades argentinas en una apetencia plural que podía reclamar tanto la fascinación de internarse en las diversas lecturas de Rayuela como tentar la aventura de las impronosticables presentaciones de Marta Minujin; congregarse en los auditorios para aclamar a los más inspirados discípulos de los Beatles, o introducirse en el mundo feérico de Julio Le Parc, el artista plástico que había deslumbrado en Venecia con su laberinto de espejos flotantes.

Cortázar y sus seguidores más visibles: Néstor Sánchez, Aníbal Ford, Gudiño Kieffer, capitalizaron a su favor, desde mediados de la década, el aire de los tiempos. ¿Qué grado y qué tipo de comunicación se estableció con aquellos escritores que, del otro lado de la línea, continuaron por los mismos años enfatizando las variantes realistas del relato y recibiendo parecida atención de sus lectores? Desde luego, en el nivel de notas y gacetillas literarias es posible reunir indicios de posiciones encontradas, juicios sobre autores y obras que remiten a una $\mathrm{u}$ otra concepción del hecho literario. Pero difícilmente algo que suene a polémica, a un diálogo de las proporciones que hubiera cabido esperar de la importancia y del número de los protagonistas; de las punzantes aristas de los temas abiertos a la confrontación; de la enorme caja de resonancia disponible. El artículo que David Viñas publicó en junio de 1969, Después de Cortázar: historia y privatización ${ }^{8}$, pareció, tardíamente, señalar el

"Susan Sontag, "One Culture and the New Sensibility», en Against Interpretation (New York: 1981).

${ }^{8}$ En Cuadernos Hispanoamericanos, núm. 234, Madrid, 1969. También, De Sarmiento a Cortázar (Buenos Aires: 1971). La respuesta de Cortázar, no a estas 
rumbo conjeturable de ese conjeturable diálogo. Con la reivindicación de la historia por sujeto, ese diálogo hubiera apuntado a convertirse en la versión nacional del debate con que los intelectuales europeos acompañaron los progresos del estructuralismo en la mitad de los sesenta.

Pero no se produjo en los términos de la década. Demasiado ruido, acaso, para un diálogo. De armas, desde luego; de puertas de universidades que se cerraron con estrépito; de rumores que estallaron finalmente en violentas manifestaciones callejeras. Pero también de slogans publicitarios que anunciaban la felicidad al alcance de cada presupuesto; de listas de best-sellers que golpeaban incesantemente la retina de ávidos lectores; de estrellas de cualquier tipo de excelencia que disputaban su lugar en la tapa de los semanarios o alimentaban la máquina de imágenes de las mesas redondas televisadas. Sin contar con que Julio Cortázar, el interlocutor válido, azoraba a tirios y troyanos con el anuncio de su descubrimiento de América Latina y de la revolución cubana desde el mirador de París. Una forma de reivindicación personal, sin duda. Pero una forma que desplazaba el eje de significación de la historia del ámbito de la nación, o lo subordinaba en términos de volver apenas relevante su esfera de gravitación ${ }^{9}$.

Sin diálogo entonces, pero con una novela que intentará denodadamente soldar los puentes entre la moral y la gracia, la vida y el arte, concluirá, simbólica y casi cronológicamente, la producción narrativa de los sesenta. El camino de los hiperbóreos (1968), de Héctor Libertella, es una suerte de Adán Buenosayres de la edad de los alucinógenos, la destrucción de las formas, la búsqueda desesperada de la autenticidad. Pero su protagonista no hablará desde una distancia en donde el humor y el resentimiento se equilibran; hablará sin mediaciones, desde el límite frágil en el que la experiencia se convierte en el registro apto para todas las transmutaciones. Y como el Johnny Carter de «El perseguidor», quemará sus naves, pero mantendrá siempre la lucidez de sus actos; se perderá a sí mismo, pero sin cortar las amarras con el universo cotidiano.

Nacido a la literatura en plena eclosión del experimentalismo, sin tradición a la espalda que aligerar, Libertella se sumerge en el nuevo

notas, sino a una entrevista a Viñas publicada por Hispamérica en su número inicial, apareció en esta misma revista, año 1, núm. 2, 1972.

${ }^{9}$ El corte cronológico de la década no clausuró, por supuesto, los flancos abiertos del debate, $\mathrm{y}$ en los años setenta se produjeron interesantísimas variantes: en el mismo. La aparición de El libro de Manuel fue, de alguna manera, una respuesta demorada a las provocaciones polémicas de los años anteriores. 
lenguaje como en su elemento natural. Sin esa resistencia, sin esa tentación de deslumbramiento que acecha en cada combate ganado a la costumbre, el lenguaje es tanto el instrumento idóneo de la narración como el componente regular del universo narrado. De su dislocación, su reverso paródico, sus licencias lúdicas, sus caídas en la irresponsabilidad o sus huecos de sentido. Un universo en el que se apuesta al riesgo de producir una obra de arte que no sea momificada por las instituciones, y de vivir, al mismo tiempo, una vida que se justifique a sí misma como obra de arte.

Libertella recorre y hace recorrer al lector esa aventura con la falta de solemnidad característica de toda la nueva narrativa. Pero esa falta de solemnidad no evita el efecto devastador de esa incursión por la geografía, los hombres y las instituciones del país. Crítica de la vida y extensión de la vida; mensaje cruzado y pura exaltación del relato. El capítulo final, «Llegada del artista a Buenos Aires», vale casi como un descenso de Orfeo a los infiernos. De un Orfeo que había podido anticipar y anticiparse: «... falta solamente que digamos no va más a este arte de hacer libros y cuadros y conciertos y conferencias y películas y que nos entreguemos humildes y anónimos a fomentar las vivencias o la creación en los pobres guardianes de la máquina. Comprendo al fin que la futura obra estética será una semilla de solidaridad fermentada en el otro... y comprendo también que será terriblemente doloroso acallar esas ganas insoportables de erigir el Gran Libro que nos Corone...»

Una carta de reconocimiento no debe ser más arbitraria que los hechos que registra. Pero no puede serlo menos. La situación de la prosa narrativa, o mejor aún, la situación de dos de las vertientes de la prosa narrativa y de sus canales de recepción, proponen una perspectiva de registro tan absorbente, que la visión sobre otros sectores del campo de producción y lectura de los años sesenta parecerá, necesariamente, restringida. Para una carta que intenta sólo seguir las líneas de fuerza y sus puntos de incidencia en un proceso, el reparo no es inhibitorio. Pero el reparo vale como una reserva sobre la que habrá que volver para desplegarla, escrupulosamente, si la guía quiere convertirse en una verdadera historia particular del período.

En el terreno mismo de la prosa narrativa hay obvias circunstancias que escapan a la atención exigida por el desarrollo de las tendencias generales o no se ajustan a su nomenclatura. Una novela como El oscuro, de Daniel Moyano, por ejemplo, que salió como Palas Atenea de la cabeza misma del aparato editorial del boom, en Buenos Aires, y que se mantuvo refractaria a seguir su circuito. O el caso de Sagrado, de Tomás Eloy Martínez, demasiado atenida al modelo de lo real maravi- 
lloso, en la versión de García Márquez, pero interesantísima en su proyecto de rescatar para la literatura la faz mediterránea de la Argentina, sin las limitaciones y los estereotipos del folklore y del costumbrismo. $\mathrm{O}$ el del ciclo de relatos de Juan José Saer, fundando rigurosamente su "Yoknapatawpha» o su "Santa María» en el norte del litoral santafesino. $\mathrm{O}$ el de las dos primeras novelas de Manuel Puig, La traición de Rita Hayworth y Boquitas pintadas, construidas en el más candoroso modo de fluencia narrativa y a las que la nueva crítica, con armas y bagajes del estructuralismo y del ya entonces posestructuralismo, convirtieron en textos preferidos de ejercitación.

El puntual registro de los estrenos y la particular dinámica del mundo del espectáculo suelen sobredimensionar el peso específico de la literatura dramática. Pero en los años sesenta, en un segmento cultural que tendió a ser fundamentalmente espectáculo y consumo de espectáculo, que tendió a reflexionar sobre él y a experimentar distintas formas de representación, lo que se advirtió fue el empeño en disolver el concepto mismo de literatura dramática, esto es, el de texto susceptible de representación. En su forma extrema, el happening excluía el texto en beneficio de la representación ${ }^{10}$. En la experiencia del antiespectáculo, tal como la propuso Alfredo Rodríguez Arias en «Aventuras», quería desconectar los elementos del lenguaje teatral, separar el gesto de dolor del movimiento corporal correspondiente, la palabra de la acción, la vestimenta del decorado. Las muy festejadas incidencias de «Help, Valentino" se armaron sobre un collage de textos transitados por todas las formas del arte y el don de improvisación de sus actores.

En todos estos casos, el texto fue la víctima sacrificada en homenaje a la representación. Pero por celebrados que fueran estos holocaustos, debe señalarse que el grueso de la producción dramática en esos años siguió apoyándose en el texto, siguió siendo fundamentalmente texto, y texto que buscaba servir de imagen especular a la situación y a los conflictos más apremiantes de su público. Fin de diciembre, de Ricardo Halac; Las patas de la sota, de Roberto Cossa; La fiaca, de Ricardo Telesnik, ejemplifican bien diversas variantes del realismo que, sin ninguna violencia, podemos considerar homólogas a las contenidas en un amplio sector de la narrativa contemporánea.

${ }^{10}$ Aunque no exclusivamente referido a la experiencia teatral, el elusivo concepto de happening se aplicó a muchas de las muestras entonces conocidas. En Happenings (Buenos Aires: 1967), Oscar Massotta y otros colaboradores reunieron ensayos interpretativos, material gráfico y hasta algunas curiosas guías de happenings representados. 
Entre ambos extremos, la obra de Griselda Gambaro logró una solución de compromiso de impresionante solvencia. El desatino (1965), Los siameses (1967), El campo (1968), no sobrellevan con facilidad la experiencia de la lectura, en el sentido en el que lo permite la literatura dramática tradicional. Pero son textos sin los cuales resulta impensable una puesta en escena de la precisión de efectos con los que pudo -y puede- sobrecoger a sus espectadores. Este mismo poder revulsivo de la imagen representada lo emplea, desde otra perspectiva, Eduardo Pavlosky. Con recursos provenientes de la técnica del psicodrama, será la situación, no el texto prefijado, lo que desencadene la respuesta del espectador de sus obras Robot (1966) y La cacería (1967).

Los poetas del sesenta carecieron de audiencia, pero no de conflictos expresivos. La primera observación no aporta novedad alguna al conocido panorama de marginación de la lírica. Si se tiene presente, sin embargo, que esta observación se convalida en una década en la que los otros medios de expresión verbal ganan un nivel de audiencia excepcionalmente mayor que el que corresponde a su propia tradición, se podrá inferir que el fenómeno de la audiencia debió de registrarse con proporcional desasosiego en el campo de la producción poética.

Este desasosiego, desde luego, no será advertible en la mayoría de aquellos poetas que tenían ya probado su lenguaje y decantado su núcleo temático desde mucho antes del advenimiento de la década. Para ellos, los sesenta fueron el lugar de coincidencia con su madurez creadora, el marco cronológico puntual en el que pudieron inscribirse obras como La condición necesaria y El ojo, de Alberto Girri, o Amantes antipodas y Fuego libre, de Enrique Molina.

Autores como César Fernández Moreno y María Elena Walsh, en cambio, parecieron muy sensibles a las modificaciones producidas en el circuito de la lectura y en el de la recepción global del signo artístico. Aceptaron los hechos. Para los más jóvenes, sin embargo, fue difícil aceptar los hechos de un mundo que no entendían y con el que lograban comunicarse. Desde esta perspectiva común se comprende el afán y la urgencia con que muchos de los poetas jóvenes buscaron entonces identificarse como miembros de una generación, como parte de una estructura protectora en la que pudieran destacarse - y encontrarseantecedentes, o falta de antecedentes, temas y recursos comunes.

Se sentían habitantes de un mundo desilusionado; de un país burlado una y otra vez en sus esperanzas por los manipuladores del poder. $Y$ se sentían herederos de una lengua poética vaciada de su savia por los cultores del poema incontaminado, por los alquimistas del vocablo 
transparente. La lengua poética de Poesía Buenos Aires, desde luego. En contraposición, aceptaron como suyas algunas de las voces que venían de los años cincuenta: Juan Gelman, Leónidas Lamborghini y Alejandra Pizarnik.

La lengua conversacional, el eje narrativo, la localización anecdótica, la autocompasión, decididos tempranamente como recursos expresivos y temperatura emocional, facilitaron la condensación de muchos buenos poemas o líneas de poemas en autores como Juana Bignozzi, Eduardo D’Anna, Ricardo Plaza o Daniel Barros. El libro, sin embargo, la articulación orgánica y sostenida de estos supuestos, provino de un poeta crecido en una atmósfera intelectual distinta. César Fernández Moreno, con varias obras publicadas y un nombre aparentemente fijado para siempre en las rígidas mallas generacionales, percibió como nadie los elementos de comunicatividad que permitían la lengua conversacional y el recurso al relato (egregiamente anticipadas, por lo demás, por Nicanor Parra), y los empleó con notable eficacia en Argentino hasta la muerte (1963).

Fue, prácticamente, el único libro de poemas que logró visibilidad en el circuito editorial de la época. Un acto de excepción que, por lo mismo, rozó apenas el problema general de la audiencia. Desde otro frente, María Elena Walsh, también desandando o rectificando sus pasos, propuso una variante tan desconcertante como justa, tan antigua en su gesto como nueva en sus vías de realización. Como los juglares, unió la música al verso, pero, a diferencia de los juglares, contó para su beneficio con micrófonos y sistemas de reproducción electrotécnica que multiplicaron su campo de recepción hasta un límite probablemente inalcanzado por las avanzadas mismas del libro impreso.

La variante, por supuesto, como en el caso del teatro de vanguardia, implicó un cierto sacrificio del texto. Basta recorrer los poemas de $J u$ guemos en el mundo (1968) para advertir que sin el complemento de la música y el de las vivencias del medio en que se presentaron, los textos impresionan casi por su carácter residual. Una pérdida que no todos los contemporáneos juzgaron como pérdida, o como pérdida digna de sentimiento alguno de contricción. Entre el material reunido para caracterizar a los poetas del sesenta por Alfredo Andrés, se encuentra esta nota: "Quizá el único fenómeno poético capaz de representar a estos últimos años en los venideros sea el de María Elena Walsh. Su obra logró admirablemente una eliminación muy importante para la supervivencia de la poesía actual: la eliminación del libro, del artefacto molesto, lujoso y anticuado. La poesía necesitaba aire, luz, música para difundirse entre la gente como la bondad del sol o la frescura del agua. Nada mejor entonces que volverla a sus orígenes. Es lo que hizo María 
Elena. Convertida en juglar, inauguró el poema cero de su tiempo» ${ }^{11}$. Palabras excesivas, acaso, como las de muchos que preconizaron entonces el fin del carácter sagrado de la escritura, aunque lo hicieron, paradójicamente, en un contexto en el que la cultura impresa parecía alcanzar su máxima expansión ${ }^{12}$.

${ }^{11}$ Héctor Miguel Angeli, «Los poetas de 1960», en Alfredo Anđrés, El 60 (Buenos Aires, 1969).

${ }^{12}$ Para esta carta de reconocimiento han sido tenidos en cuenta los siguientes estudios, informes críticos o panoramas descriptivos: Guillermo Ara, «La literatura en la Argentina», en Qué es la Argentina (Buenos Aires: 1970); Andrés Avellaneda, "Literatura argentina, diez años en el sube y baja (1967-1977)», en Todo es historia, núm. 120, mayo de 1977; Angela Dellepiane, «La novela argentina desde 1950 a 1965» (Revista Iberoamericana, núm. 66, julio-diciembre 1968), y «Diez años de novela argentina» (Problemas de literatura, año 1, núm. 1, Valparaíso, 1972); Jorge Lafforgue (compilador), Nueva novela latinoamericana, vol. 2 (Buenos Aires: 1974); Seminario de crítica literaria Raúl Scalabrini Ortiz, El cuento argentino 1959-1970; Ana María Amar Sánchez y otros, La narrativa entre 1960 y 1970, núms. 119, 125 y 126 de Capítulo. La historia de la literatura argentina (Buenos Aires: 1981); Lilian Tschudi, Teatro argentino actual (Bucnos Aires: 1974); Raúl H. Castagnino, Literatura dramática argentina (Buenos Aires: 1968); Horacio Salas, Generación poética del 60 (Buenos Aires: 1975); Alfredo Andrés, El 60 (Buenos Aires: 1969). 
